\title{
Intravenous recombinant tissue plasminogen activator for acute ischemic stroke: a feasibility and safety study
}

This article was published in the following Dove Press journal:

International Journal of General Medicine

25 October 2016

Number of times this article has been viewed

Elyar Sadeghi-Hokmabadi

Mehdi Farhoudi

Aliakbar Taheraghdam

Mazyar Hashemilar

Daryous Savadi-Osguei

Reza Rikhtegar

Kaveh Mehrvar

Ehsan Sharifipour

Parisa Youhanaee

Reshad Mirnour

Neurosciences Research Center, Neurology Department, Tabriz University of Medical Sciences,

Tabriz, East Azerbaijan, Iran
Correspondence: Elyar Sadeghi-Hokmabadi Neurosciences Research Center, Tabriz Imam Reza Hospital, Tabriz University of Medical Sciences, Gholghasht Street, Tabriz, East Azerbaijan, Iran Tel/fax+984II 3340730 Email aeass@yahoo.com
Background: In developing countries, intravenous thrombolysis (IVT) is available at a limited number of centers. This study aimed to assess the feasibility and safety of IVT at Tabriz Imam Reza Hospital.

Methods: In a prospective study, over a 55-month period, any patient at the hospital for whom stroke code had been activated was enrolled in the study. Data on demographic characteristics, stroke risk factors, admission blood pressure, blood tests, findings of brain computed tomography (CT) scans, time of symtom onset, time of arrival to the emergency department, time of stroke code activation, time of CT scan examination, and the time of recombinant tissue plasminogen activator administration were recorded. National Institutes of Health Stroke Scale assessments were performed before IVT bolus, at 36 hours, at either 7 days or discharge (which ever one was earlier), and at 3-month follow-up. Brain CT scans were done for all patients before and 24 hours after the treatment.

Results: Stroke code was activated for 407 patients and IVT was done in 168 patients. The rate of functional independence (modified Rankin Scale [mRS] 0-1) at 3 months was 39.2\% $(62 / 158)$. The mortality rate at day 7 was $6 \%(10 / 168)$. Hemorrhagic transformation was noted in 16 patients $(9.5 \%)$. Symptomatic intracranial hemorrhage occurred in $5(3 \%)$, all of which were fatal. One case of severe urinary bleeding and one other fatal case of severe angioedema were observed.

Conclusion: During the first 4-5 years of administration of IVT in the hospital, it was found to be feasible and safe, but to increase the efficacy, poststroke care should be more organized and a stroke center should be established.

Keywords: stroke, developing countries, thrombolytic therapy, code team, rtPA, functional independence

\section{Introduction}

Cerebrovascular disease is the second most common cause of death in the world. It ranks sixth in disease burden and is expected to rise to fourth by $2020 .{ }^{1}$ For middle-income countries, cerebrovascular disease is the first leading cause of death and the third leading cause for disease burden. ${ }^{2}$ Intravenous thrombolysis (IVT) is an approved therapy for patients with acute ischemic stroke (AIS), ${ }^{3}$ and its safety and efficacy have been clearly established. ${ }^{4-7}$ Over $80 \%$ of all stroke deaths worldwide occur in developing countries. ${ }^{8}$ Adults in low- and middle-income countries are at a 30\% greater risk of death from noncommunicable diseases than their counterparts in high-income countries, ${ }^{9}$ nonetheless, in developing countries thrombolytic therapy for patients with AIS is available for only $1 \%-6 \%$ of patients, and mostly in urban areas. ${ }^{10-15}$ Surprisingly, in developed countries, this ratio is $>10 \%$ (up to 
$31 \%){ }^{16-18}$ The main barriers for implementation of thrombolytic therapy in developing countries are delay in arrival of patients at the emergency department (ED) after the onset of symptoms, financial constraints because of the high cost of the drug, lack of proper facilities, physicians' fear of serious side effects of the drug, shortage of facilities in rural areas, and physicians' lack of confidence in the efficacy of thrombolytic therapy. ${ }^{14,17,19,20}$ These barriers have caused concerns over whether treating acute stroke patients with thrombolytic drugs is a viable option for developing countries or not.

Iran is a developing country with stroke prevalence of 23-139 per 100,000 population. ${ }^{8,14,21}$ Incidence of stroke in Iran is considerably higher than most Western countries, with stroke occurring approximately one decade earlier in life. ${ }^{21}$ The country has 14 hospitals with the necessary infrastructure for thrombolytic therapy. ${ }^{10}$ Data regarding IVT for AIS in Iran are scarce, and the information is limited to 37 patients reported from one center at Firoozgar Hospital in Tehran. ${ }^{22}$ The overall purpose of our study was to report the feasibility as well as safety of IVT therapy for AIS in a tertiary referral university hospital of a developing country.

\section{Methods}

\section{Ethics}

This study was approved by the Regional Committee of Ethics in Tabriz University of Medical Sciences. Written informed consent was obtained from all patients or their next of kin for both inclusion in the study and treatment.

\section{Setting}

This was a prospective, observational study. Consecutively, all patients $(n=168)$ receiving intravenous recombinant tissue plasminogen activator (IV rtPA) for AIS were enrolled. This study was conducted at Imam-Reza Hospital in Tabriz, Iran, over a 55-month period, between June 2011 and December 2015.

\section{Area and setting}

Tabriz is a metropolitan city located in the northwest of Iran with a population of 1.7 million. ${ }^{23}$ Imam-Reza Hospital is the tertiary hospital which is the main referral center in the city. Annually, $>100,000$ patients visit the ED, of which $>800$ are acute stroke patients. ${ }^{24}$

\section{Prerequisites}

For IVT, this hospital provides neurology and neuro-ICU wards, stroke team personnel, computed tomography (CT) scan, and laboratory studies, available on a 24 hours a day/7 days a week/365 days of the year basis.

\section{Process}

\section{Prehospital}

If a patient being transferred to the hospital by Emergency Medical Service (EMS) is a potential candidate for thrombolytic therapy (according to the time of onset of symptoms and Cincinnati stroke scale), EMS personnel call the acute stroke phone number for prehospital notification. This mobile phone number is specified for acute stroke patients in our province, and not only EMS personnel but also all other medical personnel from other hospitals, outpatient clinics, and private offices can call it for prehospital notification. A neurologist answers all these calls.

\section{In-hospital}

In-hospital barriers for thrombolytic therapy have been previously studied. ${ }^{23}$ Since the major barriers were previously noted as being in-hospital delays (such as initial patients' assessment), a fast-track system with five simple and inexpensive quality-improvement interventions was organized for AIS patients. We aimed for early identification, rapid imaging, and laboratory analysis, which leads to shortened door-to-needle (DTN) time. ${ }^{25}$ Generally, patients with acute stroke symptoms are first visited by the ED physicians. If a patient according to time and Cincinnati stroke scale is a potential candidate for thrombolytic therapy, stroke code is activated. The first person from the stroke team visiting the patient is a neurology resident who confirms the probable stroke diagnosis based on history and physical examinations. Blood sampling and urgent nonenhanced brain CT scanning are ordered subsequently. At CT scan, if the patient does not have contraindication for IVT, the neurology resident directly transfers the patient to the neuroICU ward or cardiopulmonary resuscitation section of the ED, depending on the availability at the neuro-ICU. Laboratory studies are usually available in 20 minutes. Fibrinolysis is not delayed while waiting for the laboratory results unless there is a clinical suspicion of a bleeding abnormality, thrombocytopenia, or the patient has received anticoagulation therapy.

Data on demographic characteristics, stroke risk factors, blood pressure (BP), routine blood tests (ie, complete blood count, prothrombin time, partial prothrombin time, international normalized ratio, and blood glucose), findings of brain CT scans, time of onset of symptoms, time of arrival to the ED, time of stroke code activation, time of CT scan examination, and the time of rtPA administration were recorded. Written informed consent was obtained from all patients or their families.

An extensive neurological examination including the baseline National Institutes of Health Stroke Scale (NIHSS) was performed in all patients. All NIHSS scorings were 
recorded by physicians, all of whom had certification in NIHSS scoring. NIHSS assessments were performed before IV rtPA bolus, at 36 hours, at 7 days or discharge (which ever one was earlier), and at 3-month follow-up.

Inclusion and exclusion criteria were based on protocol published by the American Heart Association and the American Academy of Neurology. ${ }^{3}$ Since it was our first experience with AIS thrombolysis, we decided not to treat patients beyond 3 hours of symptom onset at this step. Brain CT scan was performed for all patients just before, and 24 hours after, the treatment. All patients received $0.9 \mathrm{mg} /$ $\mathrm{kg}$ of IV rtPA up to a maximum of $90 \mathrm{mg}, 10 \%$ of which was injected as a bolus dose and the remainder infused over an hour. Based on the National Institute of Neurological Disorders and Stroke (NINDS) t-PA study protocol, those with a systolic BP of $\geq 185 \mathrm{~mm} \mathrm{Hg}$ and a diastolic BP of $\geq 110$ $\mathrm{mm} \mathrm{Hg}$ were not eligible for thrombolytic therapy. ${ }^{5}$ Hence hypertension was treated using IV labetalol; occasionally injection of nitroglycerine or nitroprusside was required.

\section{Follow-up}

Clinical or telephone follow-up 2 months after treatment was obtained. Ten of our patients were lost to follow-up. At clinical follow-ups, both NIHSS and modified Rankin Scale (mRS) were obtained, and at telephone, follow-ups only mRS was obtained. The efficacy of telephone interview for assessing stroke outcome has been previously validated. ${ }^{26}$

\section{Evaluation}

The efficacy of IV rtPA therapy was assessed by rate of functional independence at 3 months (defined as mRS score of 0 or 1). The safety of IV rtPA therapy was assessed by the rate of symptomatic intracranial hemorrhage ( $\mathrm{SICH})$. $\mathrm{SICH}$ was defined as any new evidence of intracranial bleeding on CT or magnetic resonance imaging accompanied by a neurological deterioration of 4 or more points on the NIHSS score from baseline (European Cooperative Acute Stroke Study [ECASS] III definition)..$^{13}$

\section{Statistical analysis}

In this prospective study, data are expressed as mean \pm standard deviations. These analyses were performed with SPSS for Windows, version 16 (SPSS Inc., Chicago, IL, USA).

\section{Results}

Stroke code was activated for 407 patients suspected of having an acute stroke during this period. Ninety nine (24\%) patients had prehospital notification by EMS. Thrombolytic therapy was not administered for 239 patients. The common
Table I Reasons for disqualification from thrombolytic therapy

\begin{tabular}{ll}
\hline & Patients, $\mathbf{n}(\%)$ \\
\hline Intracranial hemorrhage & $64(26.8)$ \\
TIA or rapidly improving & $25(10.5)$ \\
Minor stroke (NIHSS score <4) & $14(5.9)$ \\
History of recent major trauma (<3 months) & $1(0.4)$ \\
Awakening stroke & $30(12.6)$ \\
Refractory hypertension & $6(2.5)$ \\
INR $>$ I.7 & $1(0.4)$ \\
aPTT $>40$ seconds & $8(3.3)$ \\
Seizure at onset & $6(2.5)$ \\
Conversion & $10(4.2)$ \\
Nonstroke diagnosis & $9(3.8)$ \\
Hypodensity $>$ I/3 of cerebral hemisphere & $5(2.1)$ \\
$>3$ hours since symptom onset & $32(13.4)$ \\
Patient/family refuse & $24(10.0)$ \\
Recent MI & $2(0.8)$ \\
Recent stroke & $I(0.4)$ \\
Active gastrointestinal bleeding & $I(0.4)$ \\
\hline
\end{tabular}

Abbreviations: aPTT, activated partial prothrombin time; INR, international normalized ratio; MI, myocardial infarction; NIHSS, National Institutes of Health Stroke Scale; TIA, transient ischemic attack.

reasons for disqualification from thrombolytic therapy are shown in Table 1.

Some patients had multiple criteria for exclusion, but only one was tabulated for each patient. Twenty four $(10.0 \%)$ of the patients for whom rtPA was not administered were qualified to receive thrombolysis, but they refused to be treated because of either cost or the side effect of the drug. None of the patients had thrombocytopenia at primary laboratory tests. Baseline characteristics of patients treated with IV rtPA are summarized in Table 2. The treating physicians recognized early ischemic changes in 18 baseline CT scans (17.4\%) of which four had hypodense ischemic changes in more than one-third of the hemisphere.

The rate of functional independence (mRS 0-1) at 3 months was $39.2 \%(62 / 158)$. Hemorrhagic transformation was noted in 16 patients (9.5\%) (Figure 1). SICH occurred in $5(3.0 \%)$, all of which were fatal (Figure 2). One patient developed severe urinary bleeding, which required premature cessation of IV rtPA infusion, reversal of drug effect, and blood transfusion. Another fatal case of severe angioedema was noted. The mortality rate at day 7 was $6 \%(10 / 168)$ and at 3 months $23.4 \%(37 / 158)$.

\section{Discussion}

To date, IV rtPA is an approved therapy for treating AIS patients. ${ }^{47}$ Several trials have challenged safety and efficacy of intra-arterial thrombolysis, and mechanical thrombectomy in acute stroke management. The largest, the Interventional Management of Stroke III Trial (IMS 3 trial), was suspended because of low likelihood of demonstrating significant 
Table 2 Baseline characteristics in acute stroke patients treated with IV rTPA

\begin{tabular}{|c|c|}
\hline Baseline characteristics & \\
\hline Age, years, median (IQR) & $65(54-72)$ \\
\hline Sex, male $\%$ & 58.9 \\
\hline Hypertension, \% & 57.7 \\
\hline Diabetes mellitus, \% & 19.6 \\
\hline Smoking, \% & 21.4 \\
\hline Hypercholesterolemia, \% & 16.1 \\
\hline Ischemic heart disease, \% & 22.6 \\
\hline Atrial fibrillation, $\%$ & 20.2 \\
\hline Prior stroke, $\%$ & 9.5 \\
\hline $\begin{array}{l}\text { Pretreatment systolic blood pressure, } \mathrm{mm} \mathrm{Hg} \text {, } \\
\text { median (IQR) }\end{array}$ & $140(125-154)$ \\
\hline $\begin{array}{l}\text { Pretreatment diastolic blood pressure, } \mathrm{mm} \mathrm{Hg} \text {, } \\
\text { median (IQR) }\end{array}$ & $80(80-90)$ \\
\hline Pretreatment blood glucose, mg/dL, median (IQR) & $134(|||-| 55)$ \\
\hline Pretreatment NIHSS score, median (IQR) & $14(10-19)$ \\
\hline $\begin{array}{l}\text { Median time interval between symptoms onset and } \\
\text { hospital arrival, minutes (IQR) }\end{array}$ & $75(47-104)$ \\
\hline $\begin{array}{l}\text { Median time interval between hospital arrival } \\
\text { and stroke code activation, minutes (IQR) }\end{array}$ & $5(2-15)$ \\
\hline $\begin{array}{l}\text { Median time interval between hospital arrival } \\
\text { to completing CT scan, minutes (IQR) }\end{array}$ & $20(10-30)$ \\
\hline $\begin{array}{l}\text { Median hospital arrival to IV rtPA injection } \\
\text { (door-to-needle time), minutes (IQR) }\end{array}$ & $55(40-75)$ \\
\hline $\begin{array}{l}\text { Median time interval between symptoms onset to } \\
\text { administration of IV rtPA, minutes (IQR) }\end{array}$ & $145(120-170$ \\
\hline
\end{tabular}

Abbreviations: IQR, interquartile range; IV rtPA, intravenous recombinant tissue plasminogen activator; NIHSS, National Institutes of Health Stroke Scale; CT, computed tomography.
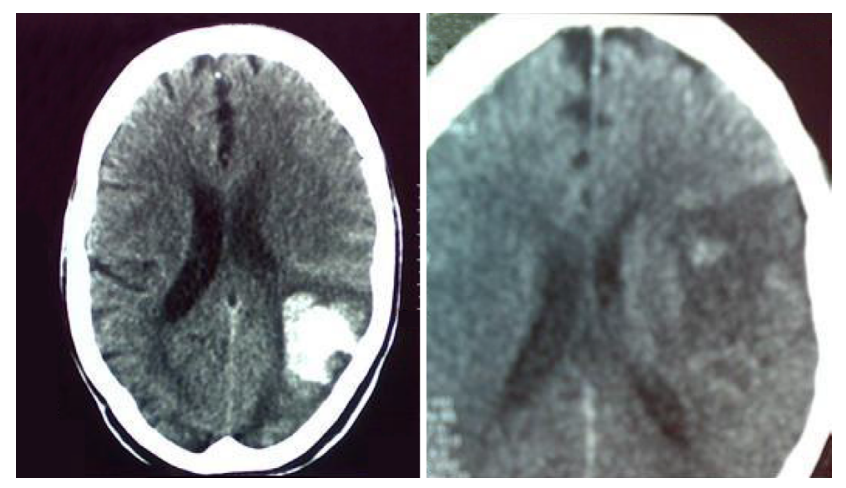

Figure I Posttreatment computed tomography scans of two patients with nonsymptomatic hemorrhagic changes.

difference between two arms of study. ${ }^{27}$ However in 2014, the positive results of Multicenter Randomized Clinical trial of Endovascular treatment for Acute ischemic stroke in the Netherlands (MR CLEAN) opened new gates to interventional treatment of stroke. ${ }^{28}$ Moreover, results from other trials supported MR CLEAN study and provided evidence that this novel therapy can work in parallel to IVT. ${ }^{29}$ Nonetheless, in low-income countries interventional treatment still has a long way to go.
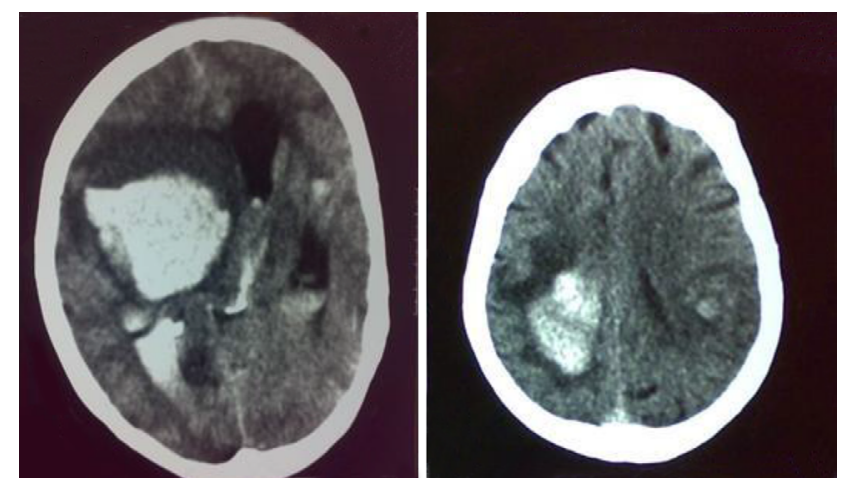

Figure 2 Posttreatment computed tomography scans of two patients with symptomatic intracranial hemorrhage.

Dramatic improvement does not occur after IVT in most patients. Furthermore, the rate of good clinical response after IVT even at more experienced centers in developed countries improvement rarely exceeds $50 \%-60 \%$ at 3-month followups. ${ }^{5,719,30-33}$ Nevertheless, IVT remains the best choice of treatment for AIS in developing countries with the shortage of expensive facilities required for other alternative such as intra-arterial thrombolysis.

According to our experience, having expensive facilities such as angiography equipment (or highly educated physicians such as interventional neurologists) is not necessary to perform IVT. The only requirements are a CT machine, a laboratory (which should be quite fast), and a neurologist.

As reported earlier, the etiology of stroke in our patients was large artery atherosclerosis in $20 \%$, cardio-aortic embolism in $45 \%$, small artery occlusion in $17.5 \%$, and undetermined causes in $17.5 \% .^{34}$

A fast-track system for thrombolysis was developed 3 years ago with our multidisciplinary stroke team consisting of neurologists and neurology residents, physicians and nurses of EDs and neuro-ICU, radiologists, and laboratory and paramedical personnel. We aimed at early identification, rapid imaging, and laboratory analysis, and finally reducing DTN time.

Based on American Heart Association/American Stroke Association (AHA/ASA) acute adult stroke guidelines, door-to-CT scan time should be $<25$ minutes and DTN time should be $<60$ minutes. ${ }^{35}$ In our study the median (IQR) door-to-CT scan time was 20 (10-30) and median DTN time was 55 (40-75) minutes. In Finland, Meretoja et al, ${ }^{18}$ after implementing 12 interventions, reported a DTN of 20 minutes and $94 \%$ of their patients were treated within 60 minutes from arrival. In the United States, the Get With the Guidelines-Stroke Program had 1,082 participating hospitals, only $26.6 \%$ of all treated patients had the DTN time of $<30$ minutes. ${ }^{36,37}$ In 2010, the AHA/ASA began an initiative to 
assist hospitals to reduce DTN time. The goal of this initiative (called "Target: Stroke") was to achieve a DTN time of $<60$ minutes in at least $50 \%$ of AIS patients. ${ }^{37}$ In our study, $59.3 \%$ of patients had DTN time of $<60$ minutes, which is acceptable, according to this goal.

Based on recent guidelines, IV rtPA administered between 3 and 4.5 hours after stroke can improve the outcome under specific criteria; however, thrombolysis was not administered for these patients since it was our first experience with AIS thrombolysis. ${ }^{38}$

In the present study, patients had a lower rate of SICH compared to the NINDS rtPA trial (3\% vs 6.4\%) and the pooled analysis of eight major randomized placebo-controlled trials of rtPA (Alteplase) for acute stroke treatment ( $3 \%$ vs 5.2\%). ${ }^{5}$ Other observational studies from developing countries show a similar rate of $\mathrm{SICH}$, which ranges from $0 \%$ to $5.9 \%$ between different centers. ${ }^{11,13,19,39-41}$

Physicians should be aware of other less common side effects of the drug, notably angioedema. We had one fatal case of angioedema, which shows the importance of regular tongue examination for enlargement during and after rtPA administration. There was another case of severe urinary bleeding which could possibly be due to aggressive bladder catheterization.

Table 3 compares the present study and other studies for functional independence (mRS $0-1)$ and mortality rate at 3-month follow-up. Compared to these studies, our results show higher mortality rate. However, the hemorrhagic transformation after IV rtPA administration, 7-day mortality rate in our center, and 3-month follow-up results are comparable with other studies (SITS-MOST ${ }^{31}$ ). It is believed that poststroke care for our patients was not satisfactory. All our patients were admitted and treated in neuro-ICU not a stoke unit. There is a clear association between the level of acute stroke care and patient outcome. ${ }^{18,42}$ Stroke patients during hospital stay after IV rtPA treatment need special consideration regarding nutrition, prevention of aspiration, bed sores, infections, physiotherapy, and so on. This care is better in stroke centers than general neurology wards. ${ }^{41}$ Moreover, in our region, there is no access to nursing homes. Our patients should be well enough to go home, or they should stay in hospital until their functions improve. This results in longer hospital stays and more vulnerability to side effects of hospitalization, and raises the mortality and morbidity rates.

Previous reports from Asian centers are scarce. ${ }^{11,13,19,22,39,40}$ This is the third report of safety and feasibly of IV rtPA from Iran. Mehrpour et al reported the safety of IV rtPA for 37 patients at Firoozgar Hospital. The rate of all hemorrhagic transformations was $24 \%$ and the rate of symptomatic hemorrhage was $7 \%$. Late outcome and mortality rate of their patients have not been reported yet. ${ }^{22}$ In another report from Ghaem Hospital, 14 patients were treated with IVT. In another study, $50 \%$ of participants ( 7 of 14) had favorable outcomes (mRS scoring 0-1) at 3-month follow-up, none of them had $\mathrm{SICH}$, and none died at 3-month follow-up. However, the later study had a small sample size compared to the present study. ${ }^{43}$

Annually, $>800$ acute stroke patients visit our hospital's $\mathrm{ED} ;{ }^{24}$ consequently the rate of thrombolysis for AIS patients is $\sim 4.6 \%$. It seems comparable or higher when compared with data from other developing countries. ${ }^{11,13}$

Significant delays still exist in transporting acute stroke patients to hospital and in administrating IV rtPA after arrival as well. There is an organized system for prehospital notification by EMS, but only $24 \%$ of treated patients with rtPA were transported by EMS. An important factor for reducing in-hospital delay is early recognition of stroke signs from patients in our overcrowded ED. Our future plans include more public education, working closely with EMS to recognize stroke symptoms earlier and notify the stroke team before arrival at the hospital, and shortening the time between the onset of the symptoms and arrival at the ED. In order to minimize DTN time, it has been planned to improve our fast-track thrombolysis system. In future, more infrastructure

Table 3 Rate of functional independence (modified Rankin Scale 0-I) and mortality at 3-month follow-up in this study, other trials, and observational studies

\begin{tabular}{|c|c|c|c|c|c|c|c|c|c|}
\hline Characteristics & $\begin{array}{l}\text { Current } \\
\text { study }\end{array}$ & NINDS $^{5}$ & SITS-MOST ${ }^{32}$ & $\begin{array}{l}\text { Pooled } \\
\text { analysis }^{5, a}\end{array}$ & $\begin{array}{l}\text { Rudolf } \\
\text { et } \mathbf{a l}^{31}\end{array}$ & $\begin{array}{l}\text { Sharma } \\
\text { et al }{ }^{19}\end{array}$ & $\begin{array}{l}\text { Chiu } \\
\text { et } \mathbf{a l}^{33}\end{array}$ & $\begin{array}{l}\text { Nguyen } \\
\text { et } \text { al }^{13}\end{array}$ & $\begin{array}{l}\text { Muengtaweepongsa } \\
\text { et } \mathrm{al}^{4 !}\end{array}$ \\
\hline Sample size $(\mathrm{N})$ & 168 & 312 & 464 & 463 & 31 & 130 & 30 & 121 & 100 \\
\hline Year & 2015 & 1995 & 2007 & 2010 & 2011 & 2006 & 1998 & 2010 & 2009 \\
\hline 3-month mortality & $23.4 \%$ & $17 \%$ & $11.3 \%$ & $13.9 \%$ & $12.9 \%$ & $13 \%$ & $23 \%$ & $12.5 \%$ & $14 \%$ \\
\hline 3-month favorable & $39.2 \%$ & $39 \%$ & $39 \%$ & $41 \%$ & 74.2 & $59 \%$ & $30 \%$ & $34.2 \%$ & $42 \%$ \\
\hline
\end{tabular}

Notes: aPooled analysis of ECASS, ATLANTIS, NINDS, and EPITHET trials; ${ }^{5}$ related to 0-90 minutes of symptom onset; 'related to $90-180$ minutes of symptom onset. Abbreviations: NINDS, National Institute of Neurological Disorders and Stroke; SITS-MOST, Safe Implementation of Thrombolysis in Stroke-Monitoring Study; ECASS, European Cooperative Acute Stroke Study; ATLANTIS, Alteplase Thrombolysis for Acute Noninterventional Therapy in Ischemic Stroke; EPITHET, Echoplanar Imaging Thrombolysis Evaluation Trial. 
will be needed to organize a stroke unit to provide better care to stroke patients.

\section{Limitations}

Our study had some limitations. First, it is a single-center study, and similar results must be reproduced by other centers to confirm the safety of thrombolytic therapy in the country. Second, based on ethical limitations, we could not set a control group not receiving IV rtPA to compare the results of the two groups and observe the efficacy of the drug more precisely.

During the first 4-5 years of administration of IVT in our center, IVT was found to be feasible and safe, but to increase the efficacy, poststroke care should be more organized and a stroke center should be established.

\section{Acknowledgments}

The authors would like to acknowledge Dr Mohammad Yazdchi and Dr Homayoun Sadeghi-Bazarghani for their outstanding help and support, which greatly assisted them in accomplishing the current study. This research was supported by the Neurosciences Research Center, Tabriz University of Medical Science.

\section{Disclosure}

The authors report no conflicts of interest in this work.

\section{References}

1. Menken M, Munsat T, Toole J. The Global Burden of Disease Study: implications for neurology. Arch Neurol. 2000;57:418-420.

2. WHO. The global burden of disease: 2004 update WHO; 2008. Available from: http://www.who.int/healthinfo/global_burden_disease/2004_ report_update/en/index.html. Accessed March 1, 2016.

3. Jauch E, Cucchiara B, Adeoye O, et al. Part 11: Adult stroke: 2010 American Heart Association Guidelines for Cardiopulmonary Resuscitation and Emergency Cardiovascular Care. Circulation. 2010;122: s818-s828.

4. Hacke W, Donnan G, Fieschi C, et al. Association of outcome with early stroke treatment: pooled analysis of ATLANT, ECASS, and NINDS rt-PA stroke trials. Lancet. 2004;363:768-774.

5. Lees K, Bluhmki E, von Kummer R, et al. Time to treatment with intravenous alteplase and outcome in stroke: an updated pooled analysis of ECASS, ATLANTIS, NINDS, and EPITHET. Lancet. 2010;375:1695-1703.

6. O'Rourke K, Walsh C, Kelly P. Safety and efficacy of IV-TPA for ischaemic stroke in clinical practice - a Bayesian analysis. Cerebrovasc Dis. 2009;28:572-581.

7. Tissue plasminogen activator for acute ischemic stroke. The National Institute of Neurological Disorders and Stroke rt-PA Stroke Study Group. N Engl J Med. 1995;333(24):1581-1587.

8. Hosseini A, Sobhani-Rad D, Ghandehari K, et al. Frequency and clinical patterns of stroke in Iran - systematic and critical review. BMC Neurol. 2010;10:72.

9. Lopez A, Mathers C, Ezzati M, et al. Global and regional burden of disease and risk factors, 2001: systematic analysis of population health data. Lancet. 2006;367:1747-1757.
10. Ghandehari K, Zahed A, Taheri M, et al. Estimation of Iranian stroke patients eligible for intravenous thrombolysis with tPA (Letter to the editor). Int J Stroke. 2009;4:236.

11. Suwanwela N, Phanthumchinda K, Likitjaroen Y. Thrombolytic therapy in acute ischemic stroke in Asia: the first prospective evaluation. Clin Neurol Neurosurg. 2006;108:549-552.

12. De Silva D, Yassin N, Toh A, et al. Timing of arrival to a tertiary hospital after acute ischaemic stroke - a follow-up survey 5 years later. Ann Acad Med Singapore. 2010;39:513-515.

13. Nguyen T, Truong A, Ngo M, et al. Patients with thrombolysed stroke in Vietnam have an excellent outcome: results from the Vietnam Thrombolysis Registry. Eur J Neurol. 2010;17:1188-1192.

14. Pandian D, Padma V, Vijaya P, et al. Stroke and thrombolysis in developing countries. Int J Stroke. 2007;2:17-26.

15. Bryer A, Wasserman S. Thrombolysis for acute ischemic stroke in South Africa. Int J Stroke. 2013;8:112-113.

16. Næss H, Waje-Andreassen U, Brøgger J, et al. Patients with acute cerebral infarction admitted to stroke unit (abstract). Tidsskr Nor Laegeforen. 2011;131:814-818. Norwegian [with English abstract].

17. Wasay M, Barohi H, Malik A, et al. Utilization and outcome of thrombolytic therapy for acute stroke in Pakistan. Neurol Sci. 2010;31:223-225.

18. Meretoja A, Roine RO, Kaste M, et al. Effectiveness of primary and comprehensive stroke centers: PERFECT stroke: a nationwide observational study from Finland. Stroke. 2010;41:1102-1107.

19. Sharma VK, Tsivgoulis G, Tan JH, et al. Feasibility and safety of intravenous thrombolysis in multiethnic Asian stroke patients in Singapore. J Stroke Cerebrovasc Dis. 2010;19(6):424-430.

20. Ayromlou H, Soleimanpour H, Farhoudi M, et al. Eligibility assessment for intravenous thrombolytic therapy in acute ischemic stroke patients; evaluating barriers for implementation. Iran Red Crescent Med J. 2014; 16(5):e11284.

21. Azarpazhooh MR, Etemadi MM, Donnan GA, et al. Excessive incidence of stroke in Iran: evidence from the Mashhad Stroke Incidence Study (MSIS), a population-based study of stroke in the Middle East. Stroke. 2010;41(1):e3-e10.

22. Mehrpour M, Aghaei M, Motamed M. Safety and feasibility of intravenous thrombolytic therapy in Iranian patients with acute ischemic stroke. Med J Islam Repub Iran. 2013;27(3):113-118.

23. Statistical Center of Iran. The results of census 2011 (AD1390): statistical center of Iran; 2012. Available from: http://www.amar.org.ir. Accessed March 1, 2016.

24. Ayromlou H, Soleimanpour H, Farhoudi M, et al. What are the most important barriers for thrombolytic therapy in ischemic stroke patients? Int J Stroke. 2013;8(4):E7.

25. Sadeghi-Hokmabadi E, Taheraghdam A, Hashemilar M, et al. Simple in-hospital interventions to reduce door-to-CT time in acute stroke. Int J Vasc Med. 2016;2016:1656212.

26. Candelise L, Pinardi G, Aritzu E, et al. Telephone interview for stroke outcome assessment. Cerebrovasc Dis. 1994;4:341-343.

27. The National Institute of Neurological Disorders and Stroke. Interventional Management of Stroke III Trial (IMS III): The National Institute of Neurological Disorders and Stroke; 2012 [cited 2012]. Available from: http://www.ninds.nih.gov/disorders/clinical_trials/IMS-III.htm. Accessed March 1, 2016.

28. Berkhemer OA, Fransen PSS, Beumer D, et al. MR CLEAN Investigators. A randomized trial for intraarterial treatment for acute ischemic stroke. N Engl J Med. 2015;372:11-20.

29. Pierot L, Pereira VM, Cognard C, von Kummer R. Teaching lessons by MR CLEAN. Am J Neuroradiol. 2015;36(5):819-821.

30. Furlan A, Higashida R, Wechsler L, et al. Intra-arterial prourokinase for acute ischemic stroke. The PROACT II study: a randomized controlled trial. prolyse in acute cerebral thromboembolism. JAMA. 1999;282(21):2003-2011.

31. Rudolf J, Tsivgoulis G, Deretzi G, et al. Feasibility and safety of intravenous thrombolysis for acute ischaemic stroke in northern Greece. Int J Stroke. 2011;6(1):91-92. 
32. Wahlgren N, Ahmed N, Davalos A, et al. Thrombolysis with alteplase for acute ischaemic stroke in the Safe Implementation of Thrombolysis in Stroke-Monitoring Study (SITS-MOST): an observational study. Lancet. 2007;369(9558):275-282.

33. Chiu D, Krieger D, Villar-Cordova C, et al. Intravenous tissue plasminogen activator for acute ischemic stroke: feasibility, safety, and efficacy in the first year of clinical practice. Stroke. 1998;29(1):18-22.

34. Pashapour A, Atalu A, Farhoudi M, et al. Early and intermediate prognosis of intravenous thrombolytic therapy in acute ischemic stroke subtypes according to the causative classification of stroke system. Pak J Med Sci. 2013;29(1):181-186.

35. Guidelines for the early management of patients with acute ischemic stroke: executive summary. American Heart Association/American Stroke Association; 2014. Available from: http://stroke.ahajournals.org/content/ supp1/2013/01/29/STR.0b013e318284056a.DC1/Executive_Summary .pdf

36. Fonarow GC, Smith EE, Saver JL, et al. Timeliness of tissue-type plasminogen activator therapy in acute ischemic stroke: patient characteristics, hospital factors, and outcomes associated with door-to-needle times within 60 minutes. Circulation. 2011;123:750-758.

37. Fonarow GC, Smith EE, Saver JL, et al. Improving door-to-needle times in acute ischemic stroke: the design and rationale for the American Heart Association/American Stroke Association's target: stroke initiative. Stroke. 2011;42:2983-2989.
38. Jauch EC, Saver JL, Adams HP, et al. American Heart Association Stroke Council; Council on Cardiovascular Nursing; Council on Peripheral Vascular Disease; Council on Clinical Cardiology. Guidelines for the early management of patients with acute ischemic stroke: a guideline for healthcare professionals from the American Heart Association/ American Stroke Association. Stroke. 2013;44(3):870-947.

39. Wasserman S, Bryer A. Early outcomes of thrombolysis for acute ischaemic stroke in a South African tertiary care centre. S Afr Med J. 2012;102(6):541-544.

40. Padma MV, Singh MB, Bhatia R, et al. Hyperacute thrombolysis with IV rtPA of acute ischemic stroke: efficacy and safety profile of 54 patients at a tertiary referral center in a developing country. Neurol India. 2007;55(1):46-49.

41. Muengtaweepongsa S, Dharmasaroja P, Kummark U. Outcomes of intravenous thrombolytic therapy for acute ischemic stroke with an integrated acute stroke referral network: initial experience of a community-based hospital in a developing country. J Stroke Cerebrovasc Dis. 2012;21(1):42-46.

42. Smith EE, Hassan KA, Fang J, et al. Do all ischemic stroke subtypes benefit from organized inpatient stroke care? Neurology. 2010; $75(5): 456-462$.

43. Nikkhah K, Avan A, Shoeibi A, et al. Gaps and hurdles deter against following stroke guidelines for thrombolytic therapy in Iran: exploring the problem. J Stroke Cerebrovasc Dis. 2015;24(2):408-415.
International Journal of General Medicine

\section{Publish your work in this journal}

The International Journal of General Medicine is an international, peer-reviewed open-access journal that focuses on general and internal medicine, pathogenesis, epidemiology, diagnosis, monitoring and treatment protocols. The journal is characterized by the rapid reporting of reviews, original research and clinical studies across all disease areas.

\section{Dovepress}

The manuscript management system is completely online and includes a very quick and fair peer-review system, which is all easy to use. Visit http://www.dovepress.com/testimonials.php to read real quotes from published authors.

Submit your manuscript here: https://www.dovepress.com/international-journal-of-general-medicine-journal 